\title{
Mycobacterium bovis: Polymerase Chain Reaction Identification in Bovine Lymphonode Biopsies and Genotyping in Isolates from Southeast Brazil by Spolygotyping and Restriction Fragment Length Polymorphism
}

\author{
MS Zanini*, EC Moreira*, MTP Lopes**, RS Oliveira***, SC Leão***, \\ RL Fioravanti****, E Roxo*****, M Zumarraga******, MI Romano******, \\ A Cataldi $* * * * * *$, CE Salas ${ }^{+}$
}

Laboratório de Biologia Molecular de Produtos Naturais, Departamento de Bioquímica e Imunologia, ICB *Escola de Veterinária **Departamento de Farmacologia, ICB, Universidade Federal de Minas Gerais, Av. Antônio Carlos 6627, 31270-901 Belo Horizonte, MG, Brasil ***Departamento de Microbiologia e Parasitologia, Escola Paulista de Medicina, São Paulo, SP, Brasil ****Laboratório Central do Estado do Espírito Santo, Vitória, ES, Brasil *****Instituto Biológico de São Paulo, São Paulo, SP, Brasil ******Instituto de Biotecnologia, Centro de Investigación en Ciencias Veterinarias, Buenos Aires, Argentina

Diagnosis of the Mycobacterium tuberculosis complex by direct PCR of mediastinal lymphnode DNA and microbiological tests were compared in cattle suspicious of bearing tuberculous-like lesions detected during slaughter.

The PCR procedure applied on DNA samples ( $n=54)$ obtained by adding $\alpha$-casein into the thiocyanate extraction mix was positive in $70 \%$ of the samples. PCR confirmed the identification of 23 samples (100\%) that grew in culture, 9 samples (60\%) that failed to grow in culture, plus 6 (37.5\%) samples that resulted in growth of bacterial contaminants. Genotyping by IS6110-RFLP and DR-spoligotyping analysis of seven samples revealed the presence of several polimorphisms. Seven of the isolates contained multiple copies of IS6110, thus defining the existence of five singular genotypes.

Key words: Mycobacterium bovis diagnosis - DNA polimorphism - thiocyanate guanidinium - Brazil

Bovine tuberculosis is an important zoonosis worldwide. Mycobacterium bovis, the causative agent of this disease in cattle, is also a pathogen for man and other economically important animals. M. bovis is a member of the M. tuberculosis complex, a group that includes also $M$. tuberculosis, M. africanum and M. microti.

In Brazil, the prevalence in animals is estimated between 0.9-2.9\% (Kantor \& Ritacco 1994). Therefore, between 1.35 and 4.35 million cattle might be contaminated with the microorganism. In humans, diagnosis relies on clinical manifestations, skin testing and subsequent identification of the bacteria by Ziehl-Neelsen (ZN) stain and microbiological tests. Unfortunately, culturing sample isolates requires 4-6 weeks to attain the desired cell

\footnotetext{
This work was supported by Fapemig and CNPq. ${ }^{+}$Corresponding author. Fax: +55-31-399.2646. E-mail: cesbufmg@mono.icb.ufmg.br

Received 17 October 2000

Accepted 17 April 2001
}

growth needed for identification. Moreover, although the ZN procedure is fast, it lacks specificity and sensitivity. A similar situation is observed during the diagnosis of $M$. bovis in animals. McIlroy et al. (1986) reported that upon diagnosis of tuberculin-positive animals, tuberculous lung lesions were evident in $70 \%$ of reactive cattle, while M. bovis was isolated from nasal or tracheal mucus samples in just $19 \%$ of confirmed cases. These discrepancies illustrate the need for more sensitive and accurate methods to assist in the control of this zoonosis.

PCR has been successfully applied by us and other groups to detect members of $M$. tuberculosis complex. DNA amplification of specific sequences of DNA by the PCR technique has been reported to provide rapid diagnosis of many diseases and is especially useful for the direct detection of M. bovis in bovine tissue samples (Kolk et al. 1992, Kox et al. 1994, Liebana et al. 1995, Wards et al. 1995, Vitale et al. 1998, Zanini et al. 1998, Romero et al. 1999). By and large, the success of PCR depends on the availability of DNA, free of contaminants that impair the amplification process. The isola- 
tion of DNA with thyocianate-diatomaceous silica is an efficient technique to release DNA from various sources. However, the presence of impurities in the DNA solution that interfere with the PCR remains as an obstacle for universal adoption of this technique (Kolk et al. 1992). A recent study shows that addition of $\alpha$-casein can circumvent this problem (Boom et al. 1999). We adopted this procedure to identify in lymph node, from slaughtered animals bearing macroscopic lesions, the presence of $M$. tuberculosis complex, by PCR, and compare it with culturing techniques.

The most widely used genotyping method is DNA fingerprinting in which the insertion element is IS6110; it is recommended if the typing status of the population is unknown. IS6110 produces extensive fingerprint diversity among $M$. tuberculosis (Yang et al. 1998). Although the IS6110-RFLP method is not the best choice for typing $M$. bovis isolates that have a single copy of IS6110, especially, if compared with procedures that measure direct repeats (DR) or the polymorphic GC-rich sequence (PGRS), its use is recommended for the typing of isolates with multiple copies of IS6110 (Cousins et al. 1998). One of the limitations of RFLP-based typing systems is the requirement of a well grown culture for DNA extraction. The timelag between isolation of M. tuberculosis complex from a clinical sample and the growth of a mycobacterial culture is often too long (Suffys et al. 1997).

Recently, an alternative typing technique has been developed, spoligotyping (Kamerbeek et al. 1997), based on the enzymatic amplification of the DR locus of $M$. bovis. This method detects the presence or absence of spacers within the DR locus. The resolving power of spolygotyping is preferred instead of IS6110-RFLP, when few IS6110 elements are present. This method can distinguish easily between $M$. tuberculosis and $M$. bovis, can be used with culture positive clinical samples, as well as directly from a specimen and has been used to identify the clonal nature of isolates (Roring et al. 2000). Along with spolygotyping, a new typing procedure involving detection of polimorphisms in $M$. bovis by hybridization with a pUCD probe of Alu I digested DNA is being reported (O'Brien et al. 2000)

Having shown the presence of $M$. bovis in various isolates from Southeast Brazil we further characterized the samples collected in different sites by IS6110-RFLP and DR-spacer spolygotyping, to determine their degree of relatedness.

\section{MATERIALS AND METHODS}

The samples used in this study from 54 slaughtered bovines showing tuberculous-like lesions in mediastinal and retropharyngeal lymph nodes were collected at four slaughterhouses located in Southeast Brazil (Ituiutuba, Divinópolis and Sabará, State of Minas Gerais; Colatina, State of Espírito Santo) during years 1998-1999. No more than one sample was selected per animal. The samples were (2-5 g) decontaminated by rinsing with a $6 \% \mathrm{H}_{2} \mathrm{SO}_{4}$ solution during $30 \mathrm{~min}$ at room temperature, as previously described (Marks et al. 1972). A fraction of each sample used for culture was seeded in Lowenstein-Jensen (L-J) medium, without glycerol, or in Stonebrink medium and incubated at $37^{\circ} \mathrm{C}$ for 45 days. At this time, positive identification of M. bovis was confirmed by ZN stain and biochemical tests [pyruvate, niacin, nitrate reduction, urease, pyrazinamidase and catalase activities and inhibition by thiofeno- 2 carboxylic acid and $p$-amine salicylic acid (PAS) in glutamateadded egg solid medium (without glycerol) (Romano et al. 1996)]. M. tuberculosis H37Rv, was used as the reference strain.

$P C R$ - The PCR and DNA extraction of each specimen was done as follows: $100 \mathrm{mg}$ of tissue was homogenized in $1.2 \mathrm{ml}$ of buffer $20 \mathrm{mM}$ Tris$\mathrm{HCl} \mathrm{pH} \mathrm{7.0,} \mathrm{containing} 1.2 \mathrm{mg} \alpha$-casein, $12 \mathrm{mg}$ proteinase $\mathrm{K}, 0.5 \%$ Tween 20 and incubated for $12 \mathrm{~h}$ at $60^{\circ} \mathrm{C}$, followed by $15 \mathrm{~min}$ at $100^{\circ} \mathrm{C}$. To this suspension was added $1 / 10 \mathrm{v} / \mathrm{v}$ of lysis buffer containing $5.25 \mathrm{M}$ thiocyanate guanidinium (GuSCN), $50 \mathrm{mM}$ Tris- $\mathrm{HCl} \mathrm{pH} 6.4,20 \mathrm{mM}$ EDTA, $1.3 \%$ Triton X-100, $0.1 \% \alpha$-casein and $1.2 \%$ of diatomaceous silica (Boom et al. 1990, 1999, Kolk et al. 1992, Kox et al. 1994). Following mixing, the diatom-DNA suspension was rinsed three times with buffer $5.25 \mathrm{M}$ GuSCN, $50 \mathrm{mM}$ Tris-HCl, pH 6.4 and decanted by centrifugation $(12,000 \times \mathrm{x}$, $15 \mathrm{~s}$ ) as described by Boom et al. (1990), followed by three rinses with $10 \mathrm{mM}$ Tris, $1 \mathrm{mM}$ EDTA $\mathrm{pH}$ 8.0 (TE) at room temperature. Elution of DNA was done with $0.3 \mathrm{ml} \mathrm{TE}$, following incubation at $56^{\circ} \mathrm{C}$ for $10 \mathrm{~min}$. The DNA recovered was subjected to PCR in the presence of primers INS-1 and INS-2 from $M$. tuberculosis complex insertion sequence IS6110, as previously described (Hermans et al. 1990). A positive PCR reaction is scored when a 245 bp fragment is detected, following 6\% PAGE and silver stain.

IS6110-RFLP polymorphism - Genomic digestion of $M$. bovis DNA with $P v u I I$ and RFLP analysis was carried as described by Van Soolingen et al. (1991).

The 245 bp fragment used to probe the IS6110 sequence, was obtained by PCR with the INS1 and INS2 primers (Hermans et al. 1990). Genomic DNA of $M$. bovis was digested with restriction endonuclease $P v u \mathrm{II}$, electrophoresed through $0.8 \%$ agarose gel, and transferred to a positively charged 
nylon membrane (Amersham Pharmacia) by Southern blotting technique (Southern 1975). Briefly, DNA is denatured by 2 x 15 min incubations in $0.5 \mathrm{M} \mathrm{NaOH}, 1.5 \mathrm{M} \mathrm{NaCl}$ and neutralized by $2 \times 15$ min incubations in $0.5 \mathrm{M}$ Tris- $\mathrm{HCl}, \mathrm{pH}$ 7.5; $3 \mathrm{M} \mathrm{NaCl}$ before overnight capillary transfer in $20 \mathrm{x} \mathrm{SSC}(3 \mathrm{M} \mathrm{NaCl}, 300 \mathrm{mM}$ sodium citrate; $\mathrm{pH}$ 7.0). After transfer, the membranes were rinsed in $2 \mathrm{x} \mathrm{SSC}$ and allowed to air dry. DNA was fixed to the membrane in a hot air oven at $120^{\circ} \mathrm{C}$ for 20 $30 \mathrm{~min}$. Membranes are stored in a sealed plastic bag between $3 \mathrm{MM}$ Whatman filter paper at $-20^{\circ} \mathrm{C}$ until used.

Spolygotyping analysis - The spoligotyping was performed according to Kamerbeek et al. (1997) and Zumarraga et al. (1999). Amplification of the DR region from $M$. bovis was done with two primers specific for the DR locus. The PCR products were hybridized to a spoligo-membrane to which synthetic oligonucleotides of the DR regions of $M$. tuberculosis $\mathrm{H} 37 \mathrm{Rv}$ and $M$. bovis $\mathrm{BCG}$ were covalently bound and detected using a streptavidinperoxidase conjugate (Roche Diagnostics Ltd, UK) and the ECL (Amersham Pharmacia Biotech, UK) detection system as described (Kamerbeek et al. 1997). The membranes were kindly provided by The National Institute of Public Health and the Environment, RIVM, The Netherlands.

\section{RESULTS AND DISCUSSION}

Fifty-four biopsy samples from lymph nodes were dissected from slaughtered animals bearing tuberculous-like lesions. Following culture for 45 days (23) $42.6 \%$ grew isolates identified by biochemical testing and $\mathrm{ZN}$, as $M$. bovis. A fraction of the samples (15) failed to grow in culture representing $27.7 \%$, or contained bacterial contaminants (16) $29.6 \%$, as verified by $\mathrm{ZN}$ and biochemical reactions.

On the other hand, direct PCR from lymph nodes was positive for $M$. bovis in (38) $70.3 \%$ of the assayed samples. Each of the positive culture specimens yielded positive PCR as well (42.6\%), while (9) $60 \%$ of samples negative for culture yielded positive PCR and (6) $37.5 \%$ of contaminated cultures afforded positive PCR as well. The high levels of microbial contaminants observed is probably a consequence of the poor sanitary conditions at the slaughterhouse, since handling of specimens following collection was aseptically done. It should be mentioned that PCR was sensitive enough to detect $M$. bovis in a large proportion $(60 \%)$ of those samples that failed to grow in culture; this fact was emphasized by Liebana et al. (1995).

In a similar study, the efficiency of three methods to diagnose $M$. bovis in bovine clinical samples was compared. Again, PCR showed the highest efficiency (11.4\%), compared to bacteriological culture $(0.4 \%)$ and microscopic examination $(0.4 \%)$. Based on these figures PCR is 28.5 times more efficient than culturing and direct microscopy (Romero et al. 1999). Their data confirm the advantage of PCR for diagnosis of M. tuberculosis complex over other procedures. The effectiveness of PCR reported here is superior because we used animal tissue with visible tuberculous-like lesions, while Romero et al. (1999) samples were mostly derived from cattle with positive intradermal tuberculin reaction. Also, their sampling was done on blood, nasal secretion and milk.

On the other hand, our PCR was 1.6 fold more efficient than culturing, while their efficiency was 28.5 fold higher when comparing similar procedures. Again, this difference could be attributed to the different source of samples used in both studies.

The improved identification obtained in this study is attributed to removal of unwanted inhibitors of unknown nature by $\alpha$-casein, as our early attempts to extract DNA with GUSCN-diatomeaceous without casein reduced the efficiency of this diagnosis by $20-30 \%$ (data not shown), as previously reported (Boom et al. 1999). According to Kodavanti et al. (1996) the extraction of nucleic acids from inflamed tissue having a high influx of eosinophils by the conventional acid guanidinium thiocyanate phenol-chloroform (AGPC) procedure fails to yield intact DNA suitable for PCR or Northern blot analysis. Addition of undegraded nucleic acids samples from an inflamed lung to a total nucleic acids solution from saline control rat lung yielded electrophoretic profiles of degraded material, indicating the presence of nucleases-like activity in the nucleic acids extracted from lung tissues having an eosinophil influx. The data is interpreted as if the conventional AGPC procedure apparently fails to completely remove nucleases associated with induced pulmonary eosinophil influx.

Genotyping of the IS6110 locus revealed two $(n=2)$, three $(n=2)$ or four $(n=3)$ inserts, thus evidencing the presence of multiple copies of IS6110 in seven of these isolates (Fig. 1). The $1.9 \mathrm{~kb}$ fragment found in most $M$. bovis samples was detected in 16 isolates (not shown). Based on these profiles, the seven samples were grouped into five different genotypes. Three of them (A65/A66/A68) isolated in different areas showed similar multicopy profile composed of four IS6110 copies, while isolates A74 and A82 with three copies, and finally A19 and A69 with two insertion sequences.

Spoligotyping experiments also identified five different patterns among the isolates, three of them 


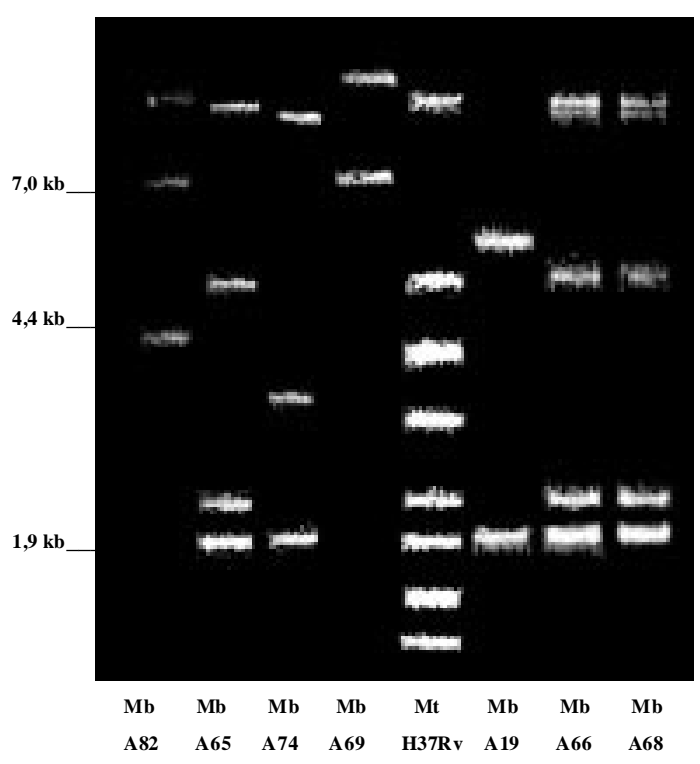

Fig. 1: RFLP analysis of Micobacterium bovis isolates from southeast Brazil. Southern blot fingerprints were obtained by hybridization with the peroxidase labeled IS6110 probe. The samples identified at the bottom are: MbA82, MbA65, MbA74, MbA69, MbA19, MbA66, MbA68. The MtH37Rv at center represents the molecular weight marker. The left ordinate shows the estimated size in kilobase pairs. Autoradiograms were exposed for $1 \mathrm{~h}$ at room temperature.

(A65/A66/A68) sharing an identical profile. Fig. 2 , shows seven spoligotypes along with a dendrogram drawn by GelCompar software, showing the relationship between the isolates. Interestingly, samples A65, A66 and A68, shared identical spoligotyping and IS6110 profiles supporting their common clonal character.

The polymorphism found in this study supports earlier data by Romano et al. (1996) that demonstrated nine different patterns using $P v u I I-d i g e s t e d$
DNA from 65 Argentinean M. bovis samples hybridized with the 245-bp probe. Gutierrez et al. (1995) also observed four different patterns of $M$. bovis in cattle and goats from Spain using $P v u I I-$ digested DNA+RFLP with IS6110 probe.

By contrary, spoligotyping of four Brazilian clusters of $M$. bovis showed a higher degree (83\%) of homology (Zumarraga et al. 1999) and a predominant single copy IS6110 genotype has been reported in bovine isolates from Argentina. Moreover, the study with Argentinean isolates, suggested that strains with multiple copies of IS6110 were originated from wild or zoo animals rather than from cattle (Zumarraga et al. 1999).

On the other hand, a comparison of the spolygotypes shown here with those reported by Zumarraga et al. (1999) on a Latin American population show that both groups lack spacers 3, 9, 16, 39-43. Also, two of the spolygotypes reported here A74 and A82, were previously described as $12 \mathrm{~S}$ or $12 \mathrm{~A}$ and $20 \mathrm{~A}$, respectively, by Zumarraga et al. (1999). The spoligotype A74, which is identical to spoligotype for $M$. bovis $\mathrm{BCG}$ was described by Zumarraga et al. (1999), in seven Argentinean bovines, eight animals other than bovine and a human isolate from Spain.

Finally, the data suggest a diversity of genotypes containing multiple copies of IS6110 in $M$. bovis from Southeast, Brazil. The state harbors near 22 million cattle heads that represent $15 \%$ of the Brazilian population. A more comprehensive analysis is under way to determine the dominant genotype in this area and also to establish whether a different genotype frequency is found in other regions of the country. It is also concluded that the PCR procedure presented can be completed within $24 \mathrm{~h}$, therefore, it can be of valuable help during sanitary inspection at slaughterhouses for condemnation of sacrificed animals suspected of having the disease.
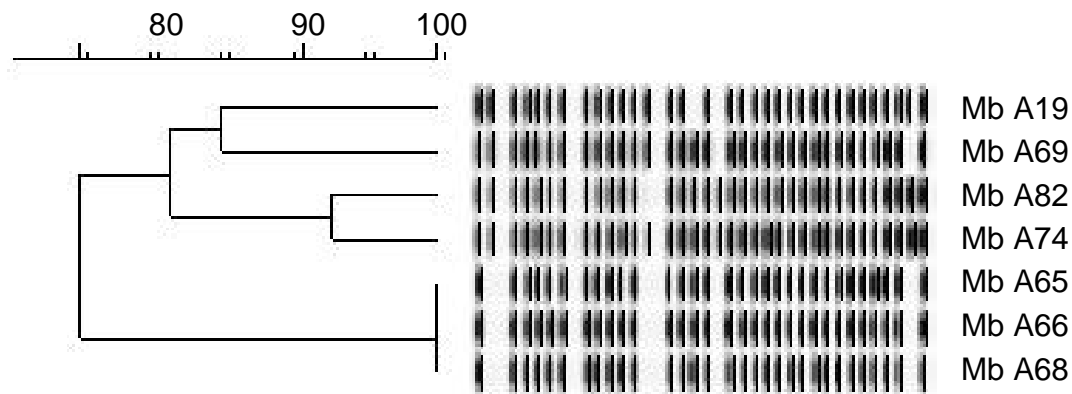

Fig. 2: dendogram and spolygotyping of seven Mycobacterium bovis isolates from Southeast Brazil. The designation on the right represents the sample identity. Each sample corresponds to one isolate. The similarity index value is presented on the upper side. 


\section{ACKNOWLEDGEMENTS}

To Dr Lucileine Ferrazoli and Erica Chimara from Setor Micobactérias, Instituto Adolfo Lutz, São Paulo, for their technical support.

\section{REFERENCES}

Boom R, Sol CJA, Salimans MMM, Jansen CL, van Dillen PME Wertheim J, van der Noordaa J 1990. Rapid and simple method or purification of nucleic acids. J Clin Microbiol 28: 495-503.

Boom R, Cees S, Beld M, Weel J, Goudsmit J, van Dillen PW 1999. Improved silica-guanidiniumthiocyanate DNA isolation procedure based on selective binding of bovine alpha-casein to silica particles. J Clin Microbiol 37: 615-619.

Cousins DV, Skuce RA, Kazwala RR, Van Embden JDA 1998. Towards a standardized approach to DNA fingerprinting of Mycobacterium bovis. Int J Tuberc Lung Dis 2: 471-478.

Gutierrez M, Samper S, Gavigan JA, Garcia-Marin JF, Martin C 1995. Differentiation by molecular typing of Mycobacterium bovis strains causing tuberculosis in cattle and goats. J Clin Microbiol 35: 3328-3330.

Hermans PWM, van Soolingen D, Dale JW, Schuitema AR, McAdam RA, Catty D, van Embden JDA 1990. Insertion element IS986 from Mycobacterium tuberculosis: a useful tool for diagnosis and epidemiology of tuberculosis. J Clin Microbiol 28: 2051-2058.

Kamerbeek J, Schouls L, Kolk A, Agterveld M, Soolingen D, Kuijper S, Bunschoten A, Molhuizen H, Shaw R, Goyal M, Embden J 1997. Simultaneous detection and strain differentiation of $\mathrm{Myco}$ bacterium for diagnosis and epidemiology. J Clin Microbiol 35: 907-914.

Kantor IN, Ritacco V 1994. Bovine tuberculosis in Latin America and the Caribean: current status, control and erradication programs. Vet Microbiol 40: 5-14.

Kodavanti UP, Jaskot RH, Bonner J, Badgett A, Dreher KL 1996. Eosinophilic lung inflammation in particulate-induced lung injury: technical consideration in isolating RNA for gene expression studies. Exp Lung Res 22: 541-554.

Kolk AHJ, Schuitema ARJ, Kuijper S, van Leeuwen J, Hermans PWM, van Embden JDA, Hartskeerl A 1992. Detection of Mycobacterium tuberculosis in clinical samples by using polymerase chain reaction and a nonradioactive detection system. J Clin Microbiol 30: 2567-2075.

Kox LFF, Rhienthong D, Miranda AM, Udomsantisuk N, Ellis K, Van Leeuwen J, Van Heusden S, Kuijper S, Kolk AHJ 1994. A more reliable PCR for detection of Mycobacterium tuberculosis in clinical samples. J Clin Microbiol 32: 672-678.

Liebana E, Arana A, Mateos A, Vilafranca M, GomezMampaso E, Tercero JC, Alemany J, Suarez G, Domingo M, Dominguez L 1995. Simple and rapid detection of Mycobacterium tuberculosis complex organisms in bovine tissue samples by PCR. J Clin Microbiol 33: 33-36.

Marks J, Jenkins PA, Tsukamura M 1972. Mycobacterium swulgai - a new pathogen. Tubercle 53: 210214.
McIlroy SG, Neill SD, McCracken RM 1986. Pulmonary lesions and Mycobacterium bovis excretion from the respiratory tract of tuberculin reacting cattle. Vet Record 118: 718-721.

O’Brien R, Danilowicz BS, Bailey L, Flynn O, Costello E, O'Grady D, Rogers M 2000. Characterization of the Mycobacterium bovis restriction fragment length polymorphism DNA probe $\mathrm{pUCD}$ and performance comparison with standard methods. J Clin Microbiol 38: 3362-3369.

Romano MI, Alito A, Fisanotti JC, Bigi F, Kantor I, Cicuta ME, Cataldi A 1996. Comparison of different genetic markers for molecular epidemiology of bovine tuberculosis. Vet Microbiol 50: 59-71.

Romero RE, Garzon DL, Mejia GA, Monroy W, Patarroyo ME, Murillo LA 1999. Identification of Mycobacterium bovis in bovine clinical samples by PCR species-specific primers. Can J Vet Res 63: 101-106.

Roring S, Brittain D, Bunschoten E, Hughes MS, Skuce RA, Van Embden JDA, Neill SD 1998. Spacer oligotyping of Mycobacterium bovis isolates compared to typing by restriction fragment length polymorphism using PGRS, DR and IS6110 probes. Vet Microbiol 61: 111-120.

Roring S, Hughes MS, Skuce RA, Neill SD 2000. Simultaneous detection and strain differentiation of Mycobacterium bovis directly from bovine tissue specimens by spoligotyping. Vet Microbiol 74: 227-236.

Southern EM 1975. Detection of specific sequences among DNA fragments separatede by gel electrophoresis. J Mol Biol 97: 503-517.

Suffys PN, Araujo MEI, Degrave WM 1997. The changing face of the epidemiology of tuberculosis due to molecular strain typing - A review. Mem Inst Oswaldo Cruz 92: 297-316.

Van Soolingen D, Hermans PWM, de Haas PEW, Soll DR, van Embden JDA 1991. Occurrence and stability of insertion sequences in Mycobacterium tuberculosis complex strains: evaluation of an insertion sequence-dependent DNA polymorphism as a tool in the epidemiology of tuberculosis. J Clin Microbiol 29: 2578-2586.

Vitale F, Capra G, Maxia L, Reale S, Vesco G, Caracappa S 1998. Detection of Mycobacterium tuberculosis complex in cattle by PCR using milk, lymph node aspirates, and nasal swabs. J Clin Microbiol 36: 1050-1055.

Wards BJ, Collins DM, Lisle GW 1995. Detection of Mycobacterium bovis in tissues by polymerase chain reaction. Vet Microbiol 43: 227-240.

Yang Z, Barnes PT, Chaves F, Eisenach KD, Weis SE, Bates JH, Cave MD 1998. Diversity of DNA fingerprints of Mycobacterium tuberculosis isolates in United States. Clin Microbiol 36: 1003-1007.

Zanini MS, Moreira EC, Lopes MTP, Mota P, Salas CE 1998. Detection of Mycobacterium bovis in milk by polymerase chain reaction. $J$ Vet Med B 45: 473-479.

Zumarraga MJ, Marti C, Samper S, Alito A, Latini O, Bigi F, Roxo E, Cicuta ME, Errico F, Ramos MC, Cataldi A, Van Soolingen D, Romano MI 1999. Usefulness of spoligotyping in molecular epidemiology of Mycobacterium bovis related infections in South America. J Clin Microbiol 37: 296-303. 